\title{
Livestock Market Chain Analysis: The Case of Live Cattle in Hadiya Zone of Southern Ethiopia
}

\author{
Amanuel Ayele \\ College of Agricultural Sciences, Wachemo University, Hossana, Ethiopia
}

\begin{abstract}
Ethiopia is known for its high potential of livestock population ranking first in Africa. However, the benefit the country is getting from the sector is far below the existing potential. Similarly in Hadiya zone, beside its high potential, the contribution of the sector is very low. Improvement of market chain is the most important way out to enhance the contribution of the sector to the country in general and to the study area in particular. The study was conducted with the aim of identifying major market channels, key actors and their major roles, opportunities and challenges, assessing marketing costs and margins, and determining factors affecting cattle market supply in the study area. The study used both primary and secondary data sources. To select representative respondents, the study employed multi-stage sampling technique. Out of ten districts of the Zone, two districts: Soro and Misha were randomly selected. Representative kebeles were randomly selected based on probability proportional to size of each district. Respondent household heads were randomly selected and interviewed to generate the data. The study also undertaken focus group discussion and key informant interview. Both descriptive statistics and econometric model were used to analyze the data. The results of the study revealed that the market chain of live cattle had long chain without adding a significant value. The determinant factors influencing live cattle market supply were households' age, educational level, market information, market price, credit utilization and number of livestock ownership. Thus, the concerned bodies should focus on the aforementioned variables for the increment of producers' margin share and live cattle market supply.
\end{abstract}

Keywords: Livestock, Live Cattle, Market Chain, Hadiya Zone

DOI: $10.7176 / \mathrm{JBAH} / 11-21-03$

Publication date: November $30^{\text {th }} 2021$

\section{INTRODUCTION}

Livestock plays a vital economic and social role in the lives of pastoralists, agro-pastoralists, and smallholder farm households in Ethiopia. Ethiopia has the largest livestock population in Africa (CSA, 2014/15). The livestock sector has been contributing considerable portion to the country's economic development in general and agricultural and rural development in particular. It contributes $40 \%$ of the agricultural Gross Domestic product (GDP) and 18\% of total GDP (CSA, 2011/12). Livestock and livestock products are also important contributor to export earnings (Stroebel, 2004 \& AGP, 2013). Live animal and meat exports are an important and growing sector of international trade for Ethiopia.

In many pastoral areas of Ethiopia, livestock are considered as a means of wealth accumulation and as indicators of status in the societal hierarchy (Belachew, 2004). The contributions of livestock can be well expressed at household level by its role in enhancing income, food security and social status (Bailey et al., 1999). The livestock sector supports the livelihoods of a large proportion of rural households in the country and may have an important role to play in rural poverty reduction strategies. The contribution of livestock to cash income of smallholders accounts for 87\% (Ahmed et al., 2003; CSA, 2007).

By considering the size of the human population that depends on livestock production in Ethiopia, the government has been supporting the development of this sector through the Livestock Marketing Authority (Asfaw et al., 2011). One of the major economic objectives of the government of Ethiopia is pursuing a policy of maximizing revenue of live animals. Ethiopia has seen some progress in the volumes exported but the numbers are not nearly as high as anticipated or needed to meet the aggressive targets laid out in the GTP, especially considering the significant livestock resources the country possesses (AGP, 2013).

Furthermore, according to Gebremedhin, Hoekstra \& Samson (2007), the levels of contributions of the livestock subsector in Ethiopia, at either the macro or micro level, is below potential. Likewise in Hadiya Zone, according to Hadiya Zone Department of Livestock and Fishery Resources (2016) report, smallholders are currently receiving only a small fraction of the ultimate value of their livestock production especially from their cattle production.

In order to improve the contribution of the sector, for the country in general and for the smallholder households in particular, analyzing livestock market chain is very imperative. Thus, this study mainly aimed at analyzing livestock market chain in the case of live cattle in Hadiya Zone of Southern Ethiopia. The specific objectives include identifying key actors and their main functions in live cattle market chains, identifying live cattle marketing channels, analyzing marketing costs and margins, and determining factors affecting market supply of live cattle. 


\section{METHODOLOGY}

Description of the Study Area

Hadiya Zone is one of the administrative Zones of Southern Nation, Nationalities and People Regional State, Ethiopia. The capital of Hadiya Zone is Hossana town. It locates about 230km South of Addis Ababa. The Zone is consists of ten rural Districts and two administrative towns. It includes three agro-ecological zones: Highland, Midland and Lowland. Majority of farm households practice mixed farming system. Livestock types kept by households in the Zone include cattle, shoat, equine, poultry and bee.

\section{Sampling Techniques and Sample Size Determination}

In the study, multi-stage sampling technique was used to draw representative samples from target population. In the first stage, out of the ten Districts of Hadiya Zone, two Districts namely Soro and Misha were randomly selected. In the second stage, five kebeles from Soro District and four kebeles from Misha District, a total of 9 kebeles were randomly selected using probability proportional to size of each District's kebeles. In the third stage, 180 representative household heads were randomly selected and interviewed from each selected kebele.

In addition, 15 cattle traders of the Zone were interviewed for gathering their data regarding cattle market chain. Key informants were also interviewed to generate relevant information regarding overall live cattle market chain in the study area. A focus group discussion was undertaken to point out challenges and opportunities of live cattle market chain actors in the study area. Moreover, market observation was carried out on major live cattle markets of the Hadiya Zone to gather data about live cattle market chain. It was undertaken in different seasons of the year in which prices and a supply of live cattle varies.

\section{Sources and Methods of Data Collection}

Both primary and secondary data sources were used to gather relevant data. Semi-structured interview schedule were prepared to gather data from cattle producers, market chain actors at various levels and key informants. Different secondary data sources were assessed to supplement primary data sources. Relevant literature and documents were also reviewed to provide theoretical background.

\section{Method of Data Analysis}

In the study both descriptive statistics and econometric model were used to analyze the data. The respondents' demographic and socio-economic conditions as well as institutional factors were analyzed using descriptive and inferential statistics. To analyze the performance of live cattle markets, margin analysis was used. The cost and price information were used to construct marketing cost and margin.

\section{Econometric analysis}

James Heckman has proposed an alternative to the maximum likelihood method, which is comparatively simple (Heckman, 1979). His model consists of a two-step estimating procedure. The first stage, a participation equation, attempts to capture factors affecting participation decision. The second stage examines factors that determine the level of participation. The probability of participation was modeled by Maximum Likelihood Probit, from which the inverse Mill's ratios will be estimated. The specifications for Heckman's two-stage models are as follows:

i. The participation Equation: The Probit model is specified as:

$$
\begin{aligned}
& Y_{i}=X_{i} B_{i}+e_{i}, i=1,2,3 \ldots n \\
& Y_{i}^{*}=\left\{\begin{array}{c}
1 \text { if } Y_{i}^{*}>0 \\
0 \text { if } Y_{i}^{*} \leq 0
\end{array}\right\}
\end{aligned}
$$

Where, $Y_{i}^{*}$ is the latent dependent variable which is not observed and $Y_{i}$ is a binary variable that assumes 1 if household $i$ sell live cattle and 0 otherwise. $\beta$ is a vector of unknown parameters in participation equation. $X_{i}$ is a vector of explanatory variables in the Probit regression model. $\varepsilon_{i}$ is random error term that are assumed to be independently and normally distributed with zero mean and constant variance.

ii. Regression (OLS): Outcome equation specified as:

$$
Q_{i}=Z_{i} \alpha_{i}+\mu \lambda_{i}+\eta_{i}
$$

Where: $Q_{i}$ is the quantity of live cattle supplied to market in the survey year. $\alpha_{i}$ is a vector of unknown parameters to be estimated in the quantity supply equation. $Z_{i}$ is a vector of explanatory variables determining the quantity supplied. $\mu$ is the parameter that helps to test whether there is a self-selection bias in market participation. $\eta_{\mathrm{i}}$ is the error term.

Lambda, which is related to the conditional probability that an individual household will decide to participate (given a set of independent variables), is determined by the formula: 


$$
\begin{aligned}
& \lambda_{i}=\frac{(F \chi \beta)}{1-F(\chi \beta)} \\
& \text { Where, } f(\chi \beta) \text { is density function and } 1-F(\chi \beta) \text { is distribution function }
\end{aligned}
$$

\section{RESULT AND DISCUSSION}

\section{Demographic features of the respondent}

The respondents consist of both male and female headed households. Out of the total producer respondents about 84.4 percent of the respondents were male headed households and the remained 15.6 percent of the respondents were female headed households. There was a significant proportionate sex difference between live cattle market participants and non-participants at 10 percent level of significance. The age of the respondent households ranged from 35 to 72 . An average age of the respondents in the study area was 45.5 years. There was a significant mean age value difference between live cattle participants and non-participants at 5 percent significance level.

In the study area, the household size is indicated as a proxy for labor input for agricultural production activities. Household size ranges from a minimum of 2 members up to a maximum of 13 members. In the study the household size was measured in terms of adult equivalent unit. An average household size in the study area was 6.56 adult equivalent units. There was a significant household size mean difference between live cattle market participants and non-participants at 1 percent significance level.

Table 1: Mean and proportion difference tests of variables between live cattle market participants and

\begin{tabular}{|c|c|c|c|c|}
\hline Variables & $\begin{array}{l}\text { Overall } \\
\text { Mean/ } \\
\text { Proportion }\end{array}$ & $\begin{array}{l}\text { Participants } \\
\text { Mean/ } \\
\text { Proportion }\end{array}$ & $\begin{array}{l}\text { Non-participants } \\
\text { Mean/ } \\
\text { Proportion }\end{array}$ & t/ $\chi^{2}$-value \\
\hline \multicolumn{5}{|l|}{ Dummy variables } \\
\hline $\operatorname{Sex}($ male $=1)$ & 0.84 & 0.89 & 0.80 & $2.604 *$ \\
\hline $\begin{array}{l}\text { Extension services (have extension } \\
\text { contact=1) }\end{array}$ & 0.88 & 0.89 & 0.87 & 0.143 \\
\hline Credit service (credit used $=1$ ) & 0.34 & 0.52 & 0.22 & $14.07 * * *$ \\
\hline $\begin{array}{l}\text { Market information (have information } \\
\text { access }=1 \text { ) }\end{array}$ & 0.49 & 0.75 & 0.30 & $3.297 * * *$ \\
\hline \multicolumn{5}{|l|}{ Continuous variables } \\
\hline Educational level & 2.94 & 3.1 & 2.81 & -0.61 \\
\hline Age & 47.49 & 45.94 & 48.91 & $2.24 * *$ \\
\hline Household size (adult equivalent) & 6.56 & 7.48 & 5.91 & $3.217 * * *$ \\
\hline Size of landholding (ha) & 0.74 & 0.86 & 0.63 & $3.58 * * *$ \\
\hline Livestock ownership (TLU) & 4.30 & 5.90 & 2.93 & $7.508 * * *$ \\
\hline Household income level (ETB) & 14570.51 & 13800 & 15100 & -0.694 \\
\hline Distance $(\mathrm{km})$ & 8.43 & 7.73 & 9.03 & $-2.69 * * *$ \\
\hline
\end{tabular}
non-participants

Source: Own survey result, 2018

Note: $* * *, * *$ and $*$ represent significant at 1,5 and 10 percent significance level, respectively.

\section{Socio-economic status of the respondents}

Cattle producers in the study area generate their income from different sources including livestock and livestock products sale, crops sale, petty trade, remittance and aiding institutions. An average annual income level of the respondent households in the study area was 14,558 Birr. As the result indicated, an annual income of the respondents ranges from a minimum of 2,300 Birr to a maximum of 39,000 Birr. The land resource is one of the factors of production used in the production of cattle in the study area. Land is also used for production of crops. An average land holding by cattle producers in the study area was 0.74 hectare. An average land holding by cattle market participants was 0.83 hectare. It was 0.63 hectare for non-participants. There was a significant mean value difference of land holding between live cattle market participants and non-participants at 1 percent significance level. An average livestock holding by live cattle market participants was 5.90 TLU. It was 2.93 TLU for non-participants. An average livestock holding by all respondents was $4.30 \mathrm{TLU}$. There was a statistically significant mean value difference in livestock ownership between live cattle marketing participants and non- participants at 1 percent significant level.

\section{Access to and Provision of Services in the study area}

The survey result revealed that 33.9 percent of the respondents have had borrowing experiences from different financial institutions. There was a statistically significant proportionate credit utilization difference between live 
cattle market participants and non-participants at 1 percent significance level. In this study, majority of the respondent households did not have access to market information in regard to live cattle. About 74.7 percent of the participants had access to market information and the rest 25.3 percent hadn't get any information. Out of total non-participating households 72.2 percent respondents have not obtained live cattle market information. In the study, there was a statistically significant proportionate difference in market information between participants and non-participants at 1 percent significance level.

Distance from producers' residence to the nearest live cattle market center might influence participation in live cattle marketing. In the study, an average distance for participating households was $7.73 \mathrm{~km}$ and $9.03 \mathrm{~km}$ for non-participating households. There was a statistically significant mean value distance difference between participating and non-participating households at 1 percent significance level.

\section{Major livestock markets}

Market availability is very important element in the process of exchanging products between sellers and buyers. If there is no market for selling the produces, the producers obviously cannot receive benefit from production. Cattle producers in the study area sell their produces in different markets like bush markets, primary markets, secondary markets and central markets. The major cattle markets in the study area during the survey period were Jajura, Gimbichu, Morsito, Geja, and Hossana.

\section{Transportation system for live cattle marketing}

Trekkers transport cattle from one point to another in the cattle marketing system. Traders confirmed that they use trekkers to transport cattle from the bush markets to the terminal market and trucking centers. Small traders trek cattle by themselves while large traders employ from two to four individuals as trekkers. The payment depends up on their agreement and distance from initial point to arrival market. Pastoralists consider their main function as transporting cattle on foot.

Truckers also transport cattle from one point in the cattle market system to another. They have multidirectional channels in Hadiya zone, transporting cattle to Hossana central market. The trucks on the route carry from 10 to 15 cattle units depending on the size of cattle and trucks size. Pastoralists considered the truckers' main functions as transporting cattle using vehicles, loading and unloading.

\section{Live cattle market channels, actors and their roles \\ Live cattle market channels}

Live cattle marketing channel refers to the sequential arrangements of various marketing intermediaries involved in the movement of live cattle from producers to end users. Market channel could be defined based on marketing points and market chain actors. The market channel that is defined based on destination indicates about the marketing points where the livestock or the specific commodity is travelled. Live cattle pass different paths to reach ultimate consumers. In the study area, cattle market chain includes input suppliers, producers, collectors or rural assemblers, whole sellers or traders, retailers and consumers.

Input Suppliers: Cattle market chain starts from input suppliers. The chain starts from the supply of veterinary medicine, feeds, trainings, financial inputs and other inputs to cattle producers for its production.

Cattle producers/Pastoralists: Cattle producers use different inputs to produce and sell cattle. The role of producers in the cattle market chain is converting all the input used in the production of live cattle in to marketable cattle. They mainly added a form value in the chain. They usually sell their products to local traders, medium traders/collectors and consumers both in the village and bush market.

Local traders/Small traders: they usually collect cattle from bush markets to sell on to medium and large traders. They may or may not have their own capital for marketing process. Their main functions include purchasing, price setting, giving final price, trekking, controlling the marketing process and providing market information. They usually buy cattle from pastoralists at the bush markets and sell to butchers, medium and large traders.

Assemblers/Medium traders: they buy cattle from small traders, brokers and pastoralists and sell them on to large traders. Their purchasing capacity and price determination role is relatively higher than that of small traders and pastoralists, as they have their own and other large traders' capital for cattle marketing. Some of their main functions include buying, price setting to some extent and providing market information. They play a more prominent role in determining prices than brokers, small traders and pastoralists do, but have less influence on this than large traders do.

Wholesalers/Large traders: they usually buy cattle from small traders, brokers and medium traders to sell in both the formal and informal market. They sometimes give capital to other traders to buy cattle on their behalf. Some of their main functions include buying, price setting, market searching, controlling marketing processes and providing market information. Large traders usually use trucks for transporting cattle and other actors consider them as the ultimate source of market information. 
Brokers: they are agents who serve as mediators between buyers and sellers in the live cattle market chain. They are usually expected to link buyers with sellers and facilitate the terms of exchange or transactions. There were no any legally known brokers in the area. Traditionally anybody who is in place during the live cattle marketing or price negotiation and makes facilitation activity either at market place or farm is considered as a broker. By doing so, they receive a brokerage fee from both buyers and sellers. The brokerage charge during the survey time was 50 Birr per head of cattle marketed (25 ETB from buyer and 25 ETB from seller). So, the brokers share that amount whatever their number is. Their interference is immense in the transactions of the live cattle sold without weighing scale. This is because of the fact that the pricing of the live cattle are based on body condition and eyeball estimation.

Consumers: they are the individuals who purchase and slaughter beef cattle for different purposes. Major function of consumers in cattle market is purchasing and slaughtering cattle for holidays, religious based ceremonies, weeding and sometimes for household food feeding.

\section{Pricing system of live cattle in the study area}

The price of cattle is usually determined in the market. That means the total supply of cattle and the demand for cattle in a particular market determines the prices of cattle. Either a single seller or buyer can not influence the price of cattle in the market. This is because there are many sellers and buyers in the market. The prices of cattle are fixed through bargaining between sellers and buyers.

\section{Marketing cost of live cattle}

Cattle marketing costs include all costs incurred from cattle production up to selling for ultimate consumers. These costs might include transportation cost, feed cost, storage cost, commission fees, taxes and other related costs. The average cost of transportation per cattle using truck ranges from 500 to 800 Ethiopian Birr. It depends up on the distance from point of departure to point of arrival market. For smaller distance markets traders used trekking transportation for their cattle. They make payment for laborers for trekking the cattle in terms of one round trip. It might cost a minimum of 100 Birr up to a maximum of 250 Birr depending the distance of the markets.

\section{Marketing margin}

As the result of the study indicates the marketing margin of live cattle differed from one marketing channel to another marketing channel. In the current study, the marketing margin share received by producers was lowered as a result of many middlemen involvement in the live cattle marketing process. In other words, as the live cattle market chain goes longer and involves numerous transactions between market chain actors, the producers' share of the final price reduces. This result has been observed in previous studies (Onyango, 2013 and Gebremariam and Yemiru, 2015). The largest market share receiver was wholesalers of live cattle.

\section{Determinants of live cattle market participation}

In the first-stage of Heckman two-stage, in the probit model, twelve variables were hypothesized to influence households' live cattle market participation. Out of them about seven variables were significantly influenced the probability of households' live cattle marketing participation (table3). Those variables are age of the household head, sex of the household head, educational status of the household head, market information, market price, credit utilization and number of livestock ownership.

The results of the model showed that the live cattle marketing participation by producers was generally positively related to being male household headed, having higher educational level, having god access to market information, positive perception towards market price, having access to credit utilization and number of livestock ownership measured in TLU. On the other hand, it was negatively related to the age of the farm household head, amount of household income per year and size of land holding by household head. 
Table 2: First-Stage of Heckman Two-Stage Estimation (Probit Estimation) Results of Determinants of Probability of Live Cattle Market Participation by Producing Households

\begin{tabular}{llll}
\hline Variable & Coefficient & Z-value & Marginal effect \\
\hline Age of the household head & -0.005 & $-3.70^{* *}$ & -0.006 \\
Sex of the household head & 0.041 & $1.11^{* * *}$ & 0.203 \\
Educational level & 0.075 & $2.11^{*}$ & 0.002 \\
Household size & 0.007 & 1.60 & 0.008 \\
Household income & -0.002 & 1.22 & -0.017 \\
Size of landholding & -0.029 & -0.95 & -0.009 \\
Extension contact & 0.012 & 1.44 & 0.336 \\
Market information & 0.227 & $3.85^{* * *}$ & 0.078 \\
Perception towards market price & 0.211 & $4.25^{* * *}$ & 0.260 \\
Credit utilization & 0.073 & $1.95^{*}$ & 0.074 \\
Distance & 0.019 & 1.61 & 0.009 \\
Livestock ownership & 0.192 & $2.80^{* * *}$ & 0.194 \\
Observations & & 180 & \\
LR Ch ${ }^{2}(12)$ & & $101.35^{* * *}$ & \\
Pseudo R & & 0.37 & \\
Log likelihood & & 42.56 & \\
\hline Source: & & & \\
\hline
\end{tabular}

Source: own survey results, 2018

Note: $* * *, * *$ and $*$ represent significant at 1,5 and 10 percent probability level, respectively.

\section{Demographic factors}

Age: As model result shown the age of the household head was negatively related with live cattle market participation in the study area. That means as the age of the household head increases, after certain age level, the willingness for participating in live cattle marketing was decline. In the study, as the age of the household head increased by one year the probability of participating in live cattle marketing decreased by 0.6 percent and this was statistically significant at 5 percent probability level.

Sex: Sex of the household head plays an important determining role in live cattle marketing participation in the study area. In the study, male headed households had more willingness and ability to produce and engaged in live cattle marketing participation. The reason was that female headed households in study area were more tended to participate in marketing of cattle products like butter and cheese rather than live cattle. The model result predicted that being male headed household increases the probability of participating in live cattle marketing by 20.3 percent in the study area. This was statistically significant at 1 percent probability level.

Educational level: Educational level of cattle producing households significantly determined live cattle market participation in the study area. As education level increased by one formal schooling year the probability of participating in live cattle marketing increased by 0.2 percent and this was statistically significant at 10 percent probability level.

\section{Institutional factors}

Market information: Nowadays, information is considered as an important input for production of market demand driven outputs. Market information can bring efficiency in marketing of agricultural commodities by enabling both sellers and buyers to have the right information about price and quality of commodities. In the study, market information has shown a positive relation to live cattle market participation. Having market information by cattle producing households increased the probability of participating in live cattle marketing by 7.8 percent. This was statistically significant at 1 percent probability level.

Perception towards market price: The perception towards market price per head cattle played a determining role in households' live cattle market participation. In the study, positive perception towards market price increased the probability of live cattle market participation by 26 percent. This was statistically significant at 1 percent significance level.

Credit utilization: In distant rural areas of many developing countries, access to formal credit are very difficult, and so informal sector is the main source of credit provision to farmers. The smallholder farmers are not the beneficiaries of formal lending institutions for different reasons. For instance, they face problems in providing the requiring collateral by lenders, the procedure of applying and taking out credit from these institutions is difficult for them, perceiving taking loan from formal lenders as risky and so on. As result, to obtain a loan and finance their enterprises, they usually depend on informal lenders rather than formal lenders.

Economic Resource Endowment factor

Livestock ownership: Livestock are a natural asset for poor farm households that can be sold when required. 
For rural poor livestock are indications of wealth status and can be used as a sort of insurance which helps to cope up in the times of crops damage. In the study area, many people consider that having many cattle as an indicator of being rich or higher income group. Those who have no cattle are considered as poor and may not get social acceptance, for instance, in the case of borrowing money from neighbors and local money lenders.

\section{Determinants of live cattle market supply}

The OLS regression in the second step of Heckman two-stage model estimated the determinants of live cattle market supply by farmers in the study area. In the second stage of Heckman model estimation, eleven variables were taken to identify the determinant factors that influence the live cattle market supply by farmers. Out of the eleven variables about five variables were statistically significantly influenced the live cattle market supply by farmers.

As the result of this model indicated, the number of live cattle that supplied to the market by producers was positively related to being a male headed household, higher educational status of the household head, larger household size, having extension contact with household head, having positive perception towards market prices, getting market information, credit utilization and owning larger number of livestock by the household head. But, the age of the household head, income of the household, and size of land holding by household were negatively related to live cattle market supply.

Table 3: The Second Step of the Heckman Two-Stage Model Estimation (OLS Regression) Of Live Cattle Market Supply by Producing Households

\begin{tabular}{lll}
\hline Variable & Coefficient & Z-value \\
\hline Age of the household head & -0.156 & $-2.94^{* * *}$ \\
Sex of the household head & 1.632 & 1.38 \\
Educational level & 1.994 & 1.85 \\
Household size & 0.376 & 1.75 \\
Household income & -0.001 & -0.44 \\
Size of landholding & -0.001 & -1.00 \\
Extension contact & 1.924 & 1.33 \\
Market information & 0.695 & $2.29^{* *}$ \\
Perception towards market price & 3.708 & $2.36^{* *}$ \\
Credit utilization & 6.797 & $3.32^{* * *}$ \\
Livestock ownership & 2.711 & $2.40^{* *}$ \\
\hline Mills Lambda & 0.060 & $1.77^{*}$ \\
\hline Rho & 0.941 & \\
Sigma & 0.064 & \\
Lambda & 0.060 & \\
\hline Number of Observation &
\end{tabular}

Number of Observation $=180$, Censored Observation $=97$, Uncensored Observation $=83$, Wald Chi ${ }^{2}(11)=$ 10938.41(0.0000)***

Source: own survey results, 2018

Note: $* * * * *$ and $*$ represent significant at 1,5 and 10 percent probability level, respectively.

Age of the household head: The result of the study shows that the age of the household was negatively related to live cattle market supply. As the age increases by 1 year the market supply of live cattle decreased by 0.156 . It was statistically significant at 1 percent significance level.

Market information: Access to market information is an important element that helps all actors of live cattle market in the process of exchanging goods and services. In the study those individuals who get live cattle market information about the price per cattle, quality of cattle had bring more cattle to the market. Having market information for live cattle marketing increased its supply by 0.695 . This was statistically significant at 1 percent significance level.

Perception towards market price: Producers' perception towards market price per live cattle influenced the market supply of live cattle in the study area. Positive perception towards live cattle market price increased the supply of live cattle to the market by 3.708. That means as market price increased live cattle market supply also increased. The reason might be as price increased the income earned for suppliers from the sale of live cattle also increases.

Credit utilization: For poor rural households credit is very essential for production of farm commodities. In many developing countries of the world like Ethiopia rural poor households have been facing the shortage of financial resources. In the study credit utilization was positively related to live cattle market supply. In other words, as the credit utilization by cattle producers increases the live cattle market supply also increases. The reason for this result can be seen in different ways. In one way, as credit utilization increases the cattle producers might be enabled to rare more number of cattle through purchasing more inputs for their cattle production and can bring more cattle to the market. In another way, those individuals borrowed money from financial 
institutions might bring more cattle to the market for selling their cattle with the aim of making loan repayment. Livestock ownership: Livestock keeping is common in many areas of rural Ethiopia. In the study area, households serve livestock for many purposes including income generation, food source, social prestige, plough farm lands, transportation of farm produces and an alternative coping means when farm crops fail. As the result of the study indicated, livestock ownership is positively related to live cattle market supply. That means those households who holding more number of livestock have brought greater number of live cattle to the market.

\section{CONCLUSION AND RECOMMENDATIONS}

Ethiopian livestock population is ranked at first in Africa. Among livestock types cattle production is common in every parts of the country. However, the benefit obtained from this cattle production is too small generally in Ethiopia and in Hadiya Zone in particular. The study was undertaken with the aim of analyzing live cattle market chain in Hadiya Zone. The study was conducted using both primary and secondary data sources for generating the data relevant to the study. Multi-stage sampling technique was used to draw sample respondent households. The study was used both descriptive statistics and econometric model to analyze the data.

As the result of the study indicated less than half of the sample respondents participated in livestock marketing in the last year. Majority of the participated households were those household heads who have lower age, are male headed households, have higher educational level, have access to market information, have positive perception towards market price and have used credit. The results using the Heckman two-stage model shows that participation in live cattle marketing in the study area were determined by the major variables: age of the household head, sex of the household head, educational level of the household head, access to market information, perception towards market price by the household head and households' credit utilization. The determinant factor which negatively influenced the live cattle market supply in the study was age of the household head. The other significant determinant factors which have positively influenced the live cattle market supply were level of formal education by household head, access to market information, positive perception towards market price, credit utilization by household head and number of livestock ownership. Based on the findings, this study put forwards the following recommendations for the betterment of live cattle market chain in the study area:

$>$ The market chain should be shorten by removing irrelevant middlemen in the live cattle market chain with the aim of increasing the share of marketing margin by the live cattle producers

$>$ The concerned bodies should encourage farmers' farm centered training and consultancy by recruiting relevant personnel at District level or kebele level.

$>$ Government bodies and other NGOs should provide credit scheme for farm households at affordable interest rate.

\section{REFERENCES}

Aklilu, Y. (2008). Livestock Marketing in Kenya and Ethiopia: A Review of Policies and Practice. Feinstein International Center, Addis Ababa.

Agricultural Growth Project (AGP), (2013). Livestock Market Development Project. AID-663-C-12-00009

Asfaw, N., Shahidur, R., \& Berhanu, G. (2011). Livestock Production and Marketing. Development Strategy and Governance Division, International Food Policy Research Institute - Ethiopia Strategy Support Program II, Ethiopia ESSP II Working Paper 26, August 2011.

Bailey, D.V., Christopher, B. B., Peter, D. L., \& Francis, C. (1999). Livestock Markets and Risk Management Among East African Pastoralists.

Belachew \& Stuart (2003). Livestock Export Zone Study: Technical Requirements and Cost Benefit Analysis (Ethiopia \& Uganda) and Potential Export Markets for Meat and Livestock. Nairobi, Kenya.

Blaylock, J., \& Blisard, W. (1993). Women and the demand for alcohol: Estimating participation and consumption. Journal of Consumer Affairs. 27(2): 319-324.

Central Statistical Agency (CSA) (2007). Agricultural Sample Survey 2006/07. Volume II. Report on Livestock and livestock characteristics. Statistical Bulletin 388. Addis Ababa: FDRE.

Central Statistical Agency, (2011/12). Annual Agricultural Sample Survey.

Central Statistical Agency, (2014/15). Annual Agricultural Sample Survey.

Gebremariam G. G. and Yemiru T. (2015). Market chain analysis of live goats: Asaita District, Afar Regional State, Ethiopia. IIED Country Report. IIED, London. http://pubs.iied.org/10120IIED ISBN: 978-1-78431149-0

Gebremedhin, B., Hoekstra, D., \& Samson, J. (2007). Heading towards commercialization? The case of live animal marketing in Ethiopia. Improving Productivity and Market Success (IPMS) of Ethiopian Farmers Project Working Paper 5. ILRI (International Livestock Research Institute), Nairobi, Kenya. 73 pp.

Getachew, L., Hailemariam, T., Dawit, A., \& Asfaw, N. (2008). Live animal and meat export value chains for selected areas in Ethiopia. Constraints and opportunities for enhancing meat exports. Improving Market 
Opportinities. Discussion Paper No.12. ILRI (International Livestock Research Institute), Nairobi, Kenya. $56 \mathrm{pp}$.

Heckman, J. (1979) Sample selection bias as a specification error Journal of Econometrica. Vol. 47(1).

Onyango, C. (2013) Analysis of structure, conduct and performance of small ruminant stock market participants of Isiolo-Nairobi trading market, Kenya. Masters thesis. Egerton University.

Stroebel Aldo (2004). Socio-Economic Complexities of Smallholder Resource-Poor Ruminant Livestock Production Systems in Sub-Saharan Africa. Thesis submitted in partial fulfillment for the degree of Doctor of Philosophy. Free State University. Pp 51-69. 